\title{
Using community surveillance data to differentiate between emerging and endemic amphibian diseases
}

\author{
Sam Young ${ }^{1, *}$, Lee F. Skerratt ${ }^{1}$, Diana Mendez ${ }^{1}$, Rick Speare ${ }^{1}$, Lee Berger ${ }^{1}$, \\ Mike Steele ${ }^{2}$ \\ ${ }^{1}$ Amphibian Disease Ecology Group, School of Public Health, Tropical Medicine \& Rehabilitation Sciences, \\ James Cook University, Townsville, Queensland 4811, Australia \\ ${ }^{2}$ Faculty of Health, Science \& Medicine and Faculty of Business, Technology \& Sustainable Development, Bond University, \\ Gold Coast, Queensland 4229, Australia
}

\begin{abstract}
We analyzed submission data from a wildlife care group during amphibian disease surveillance in Queensland, Australia. Between January 1999 and December 2004, 877 whitelipped tree frogs Litoria infrafrenata were classified according to origin, season and presenting category. At least $69 \%$ originated from urban Cairns, significantly more than from rural and remote areas. Total submissions increased during the early and late dry seasons compared with the early wet season. Frogs most commonly presented each year with injury, followed by 'other', sparganosis and irreversible emaciation of unknown aetiology. This is the first report of Spirometra erinacei infection in this species. A high prevalence (28\%) of visible $S$. erinacei infection was found in emaciated frogs, but this was not statistically different from that in non-emaciated diseased frogs (25\%). However, 14 emaciated specimens that were necropsied all had heavy $S$. erinacei infections, and the odds of visible sparganosis were statistically greater in emaciated frogs compared with injured, non-diseased frogs. We provide a detailed case definition for a new endemic disease manifesting as irreversible emaciation, for which $S$. erinacei may be the primary aetiological agent. The lack of significant spatial or temporal patterns in case presentation suggests that this is not a currently emerging disease. We show that community wildlife groups can play a valuable role in monitoring disease trends, particularly in urban areas, but identify a number of limitations associated with passive syndromic surveillance. We conclude that it is critical that professionals be involved in establishing syndromic case definitions, diagnostic pathology, complementary active disease surveillance, and data analysis and interpretation in all wildlife disease investigations.
\end{abstract}

KEY WORDS: Amphibian disease $\cdot$ Wildlife disease surveillance $\cdot$ Emaciation $\cdot$ Litoria infrafrenata Sparganosis $\cdot$ Spirometra erinacei $\cdot$ Tree frog

Resale or republication not permitted without written consent of the publisher

\section{INTRODUCTION}

Global declines and extinctions of amphibians have been accelerating over the past 3 decades. Amphibians are the most threatened faunal taxonomic group known, with nearly one-third (32.4\%) of the world's 6260 species now threatened or extinct, and at least $42.5 \%$ in decline (Vié et al. 2009). Since 1980, rapid declines have been reported in over 400 species, with just over half of these attributed to habitat degradation and overexploitation (Stuart et al. 2004, Vié et al. 2009). Until recently, in at least 200 of these species, declines had been enigmatic, predominantly affecting stream-associated frogs in forests 
and tropical montane habitats in the Neotropics and Australia (Stuart et al. 2004). Many of these declines have now been linked to the spread of the emerging infectious disease chytridiomycosis, and the impact of this disease on frog populations is thought to represent the most spectacular loss of vertebrate biodiversity resulting from disease in recorded history (Berger et al. 1998, Daszak et al. 2003, Lips et al. 2006, Schloegel et al. 2006, Skerratt et al. 2007).

The growing importance of wildlife disease as a threat to biodiversity, human health, agriculture, aquaculture and trade has been demonstrated by recent disease outbreaks, mass mortalities and emergence of new diseases (Daszak et al. 2000). A review in Australia during 1999 and 2000 concluded that a national network to coordinate wildlife disease surveillance, diagnosis, preparedness and response was vital, following which the Australian Wildlife Health Network (AWHN) was born. Its aim is to facilitate collaborative efforts in the investigation and management of wildlife disease in support of human and animal health, biodiversity and trade (Australian Government Department of Agriculture, Fisheries and Forestry: www.wildlifehealth.org.au). One of the greatest challenges is accessing wildlife disease information collected by community groups and integrating it into a national database such as that maintained by the AWHN.

Community wildlife care groups exist in many countries for wildlife rescue and rehabilitation, and groups are active in every state within Australia. In conjunction with other groups including conservation charities and environmental consultancies, they are a valuable source of wildlife information and play an important but under-utilized role, both directly and indirectly, in wildlife disease surveillance. While wildlife rehabilitators can amass diverse and important passive surveillance data, its use is greatly limited by its inaccessibility, the lack of uniform data presentation and the inherent bias in the population sample (Harden et al. 2006). Key considerations to improve the usefulness of this data include entering all acquisition information into an affordable and readily available software program (e.g. Microsoft ${ }^{\circledR}$ Excel $\left.{ }^{\circledR}\right)$ and improving standardization of record keeping and health screening using ancillary diagnostic testing and regular post-mortem examinations (Harden et al. 2006, Pacioni et al. 2007). The Cairns Frog Hospital (CFH), a small, non-profit community group in far northern Queensland, Australia, has been receiving injured and diseased amphibians from the public since 1998. During this time, primarily hand-written information has been recorded about presenting cases, including spatial and temporal data. Cases are generally admitted to the CFH by members of the public with the aim of rehabilitation and release, and limited diagnostic pathology has been carried out. The CFH represents a model for passive community surveillance of amphibian diseases in northern Queensland.

The white-lipped tree frog Litoria infrafrenata (Anura: Hylidae) is endemic to coastal and adjacent areas of tropical northern Queensland in Australia, and throughout New Guinea (Cogger 2000). It is the largest extant tree frog and is found in a wide variety of habitats including rainforest and cultivated areas and is closely associated with rural and urban dwellings. The species is agile and arboreal, with large adhesive discs on the toes; eggs are laid in water and hatch quickly to produce free-living aquatic tadpoles. L. infrafrenata populations are considered stable, and its conservation status is Least Concern (IUCN 2010).

Adults of the cestode Spirometra erinacei (synonym $S$. erinaceieuropaei), the only species of this genus recorded in Australia, occur in the small intestine of canid and felid definitive hosts (Daly 1982). Intermediate vertebrate hosts, including humans, other mammals, reptiles and amphibians, can become infected with the larval plerocercoid stage, causing sparganosis in a range of tissues (Little \& Ambrose 2000). Sparganosis has been reported in 5 anuran species in Australia: Bufo marinus (Bennett 1978), Litoria caerulea, L. gracilenta, L. aurea and $L$. peronii (Berger et al. 2009), and heavy burdens were associated with serious disease (Berger et al. 2009). Two genetically distinct populations of $S$. erinacei were detected in Australia, with 1 common genotype occurring in the dog, fox, cat, tiger snake and a python, and a separate genotype identified in 3 common green tree frogs L. caerulea (Zhu et al. 2002). The definitive hosts for this amphibian genotype are unknown.

We are investigating emerging and endemic diseases in amphibian species in Queensland, evaluating amphibian disease surveillance techniques and facilitating integration of community surveillance data into the AWHN. Here we present analyses of CFH submission data from 1999 to 2004, report Litoria infrafrenata as a new host species for Spirometra erinacei, identify $S$. erinacei as an important pathogen of urban frogs in the Cairns region and describe a new disease syndrome in populations of $L$. infrafrenata in northern Queensland. We also show that, while community wildlife groups can play a valuable role in disease surveillance, there are important limi- 
tations associated with passive syndromic surveillance making it critical that trained professionals be involved in establishing syndromic case definitions, and for diagnostic pathology, complementary active disease surveillance and data analysis and interpretation in all wildlife disease investigations.

\section{MATERIALS AND METHODS}

We obtained submission data from the $\mathrm{CFH}$ over a 6 yr period, from January 1999 through December 2004. Litoria infrafrenata cases were classified according to information recorded about season, origin and presenting category. There were 4 seasonal groups: early wet (December to February), late wet (March to May), early dry (June to August) and late dry (September to November); 4 origin groups: Cairns city suburbs (within a $15 \mathrm{~km}$ radius to the north, west and south from the centre of the rural city of Cairns in far northern Queensland), coastal suburbs immediately north of Cairns (a narrow eastern coastal strip extending from 10 to $27 \mathrm{~km}$ north of the city centre), surrounding rural or remote towns (within a $350 \mathrm{~km}$ radius to the north, west and south from the city centre) and unknown; and 4 presenting categories: injury, sparganosis (infection with the cestode Spirometra erinacei but without emaciation), irreversible emaciation (irrespective of concurrent sparganosis), and 'other' (e.g. dermatitis, superficial tissue masses and apparently healthy frogs with no clinical signs of injury or disease; Fig. 1). Presenting categories were necessarily simplistic and syndromic because diagnosis was performed by a layperson with no training in pathology.

Frogs were classified as injured if they had visible external injuries or abnormalities consistent with trauma but otherwise appeared physically healthy. Individuals were allocated the case definition of sparganosis by visual identification of swellings in the thigh muscles and/or subcutaneously, and the presence of easily identifiable cestodes in dermal ulcerations, as long as they were not emaciated. Irreversible emaciation was classified in frogs that were visibly emaciated based on the presence of bony promi- nences and reduced muscle mass, and that did not respond to basic supportive nutritional care (occasional force-feeding of invertebrates). All other presenting cases were allocated the case definition of 'other'. A veterinary pathologist necropsied 14 individuals presenting with irreversible emaciation that subsequently died or were euthanized. For histological examination, a range of tissues was preserved in $10 \%$ neutral buffered formalin, sectioned and stained with hematoxylin and eosin for microscopic examination.

To test for significant differences between groups, a factorial analysis of variance was planned, but Levene's test for homogeneity of variance showed that the assumption of equality of variances could not be made, even with data transformation. Hence, the non-parametric Kruskal-Wallis test was used to compare the annual median number of cases from 1999 to 2004 classed by presenting category, season and origin. The following analyses were conducted in order to account for the effects of multiple variables. Within each presenting category, the median number of cases for each season and origin from 1999 to 2004 were compared. Where the Kruskal-Wallis test was found to be significant ( $<<0.05)$, separate pair-

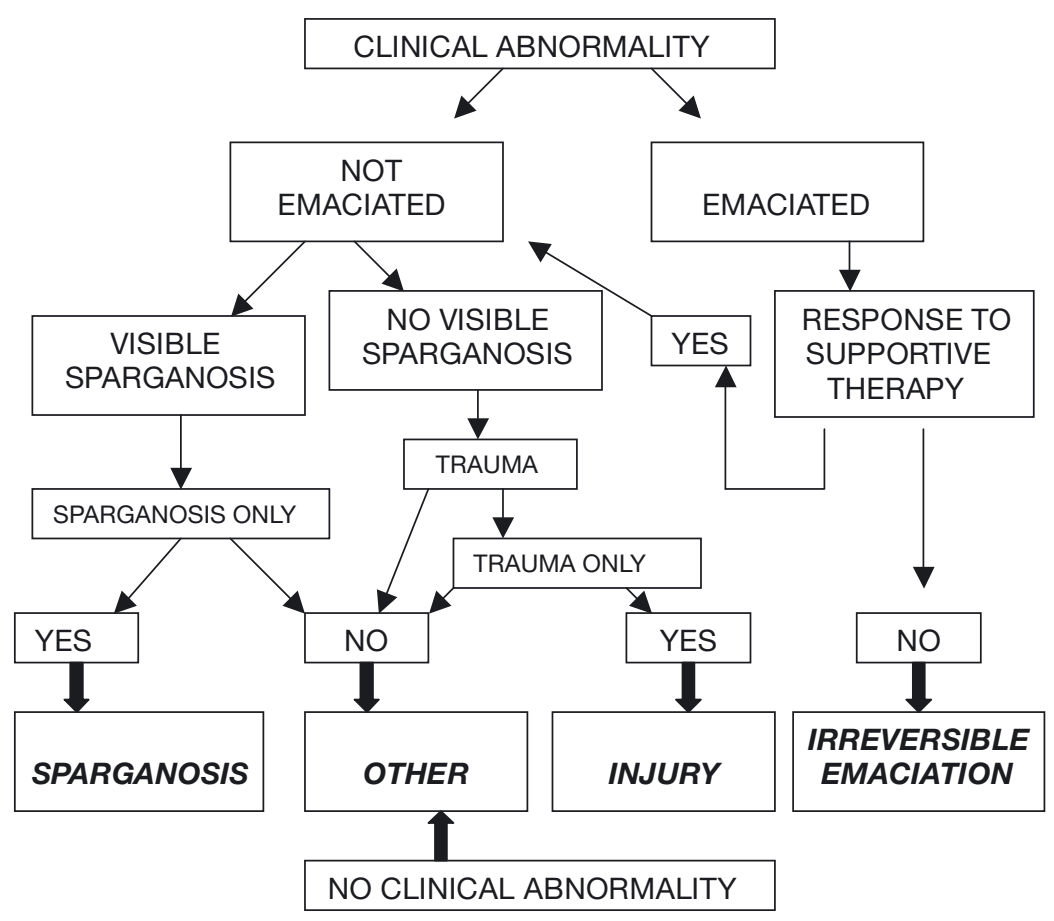

Fig. 1. Litoria infrafrenata. Decision-making flow chart for classification of white-lipped tree frog cases into 4 presenting categories. Frogs were initially classed into 2 groups, clinically normal or abnormal, by a layperson at the Cairns Frog Hospital; the abnormal frogs were then further classed according to specific clinical signs using the flow chart 
wise comparisons were done using Mann-Whitney $U$-tests with the significance level adjusted by a Bonferroni correction $(\alpha / \mathrm{n}$ where $\mathrm{n}=$ the number of comparisons) to maintain a consistent Type 1 error of 0.05 (Rice 1989). The chi-squared test for independence was used to detect temporal and spatial trends within the data set for the total number of cases submitted and for each presenting category. We used SPSS software (version 14.0) for all statistical analyses. Odds ratios (ORs) were calculated using WINPEPI software (PEPI-for-Windows version 2.6, @ JH Abramson) to identify the relationship between sparganosis and the 2 disease categories (irreversible emaciation, 'other'), compared with the injured, non-diseased frogs.

\section{RESULTS}

During the 6 yr from 1999 to 2004, 877 Litoria infrafrenata were submitted to the CFH and comprised $60 \%$ of the total post-metamorphic amphibian submissions. Over this period, L. infrafrenata cases were submitted most frequently during the late dry season, followed by the early dry, late wet and then early wet seasons each year. A significantly higher annual median number of cases (all presenting categories combined) was submitted during the early ( $\mathrm{p}=$ $0.008)$ and late $(p=0.005)$ dry seasons, compared with the early wet season (Fig. 2). Differences in submission rates between the other seasons were not significant $(\mathrm{p}>0.008$; Bonferroni-adjusted significance level). At least $69 \%$ of all cases originated from urban areas within and immediately north of Cairns; cases of unknown origin were excluded from further inter-origin comparisons. A higher annual median number of cases originated from Cairns city suburbs ( $\mathrm{p}<0.001)$ and coastal suburbs immediately north of Cairns ( $\mathrm{p}<0.001)$, compared with rural and remote areas (Table 1). There was no difference between the 2 urban categories $(p=0.020$, Bonferroni-adjusted significance level 0.017).

The most common presenting category each year was injury, followed by 'other', sparganosis and then irreversible emaciation (Table 1). A higher annual median number of cases presented with injury ( $\mathrm{p}<$ 0.001), 'other' $(p<0.001)$ and sparganosis ( $\mathrm{p}=0.008)$, compared with

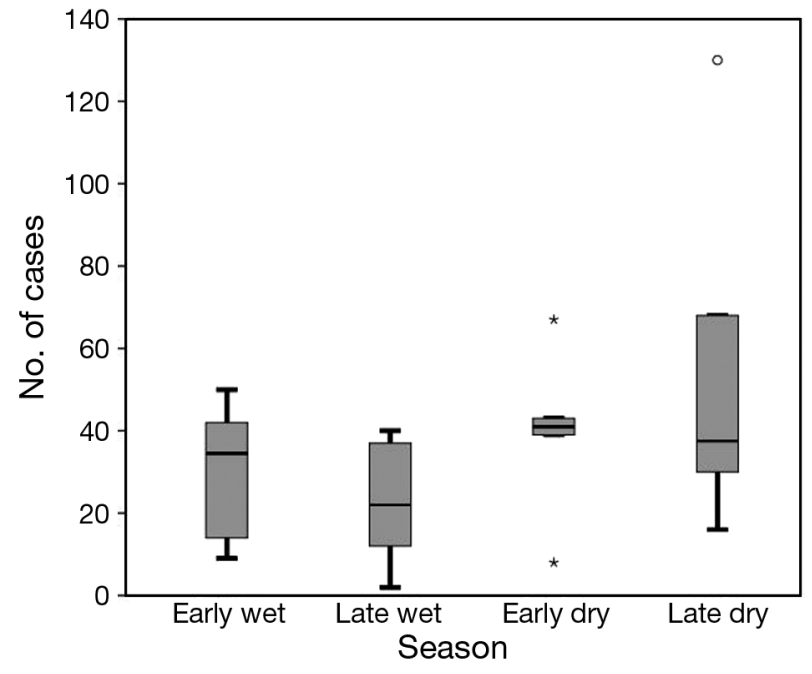

Fig. 2. Litoria infrafrenata. Distribution of white-lipped tree frog cases submitted to the Cairns Frog Hospital each season over 6 yr from January 1999 to December 2004. Each box length represents the inter-quartile range (IQR, $25-75 \%)$; the line inside the box is the median value, and the whiskers go to $1.5 \mathrm{IQR}$. ०: outliers $>1.5 \mathrm{IQR}_{\text {; }}$ *: outliers $>3$ IQR

irreversible emaciation. Differences between submission rates for the other presenting categories were not significant ( $p>0.008$, Bonferroni-adjusted significance level). An increased median number of irreversibly emaciated frogs presented during the late dry season $(p=0.007)$ compared with the early dry season, but differences between other seasons were not significant ( $\mathrm{p}>0.008$, Bonferroni-adjusted significance level; Fig. 3). There were no significant seasonal differences within the injury, sparganosis or 'other' categories ( $\mathrm{p}>0.008$; Fig. 3). The relative proportion of cases from the 4 presenting categories was

Table 1. Litoria infrafrenata. Total case numbers submitted to the Cairns Frog Hospital from January 1999 to December 2004, classified according to origin and presenting category. Values in parentheses are the relative percentages of cases in each presenting category. Values with different superscripts are significantly different $(p<0.001)$

\begin{tabular}{|lccccc|}
\hline \multirow{2}{*}{ Origin } & \multicolumn{5}{c|}{ Reason for presentation } \\
\cline { 2 - 6 } & Injury & $\begin{array}{c}\text { Irreversible } \\
\text { emaciation }\end{array}$ & Sparganosis & Other & Total \\
\hline $\begin{array}{l}\text { Cairns city suburbs } \\
\text { Coastal suburbs north } \\
\text { of Cairns }\end{array}$ & $117(40)$ & $22(28)$ & $115(53)$ & $159(56)$ & $413^{\mathrm{a}}$ \\
$\begin{array}{l}\text { Surrounding rural and } \\
\text { remote areas }\end{array}$ & $13(4)$ & $3(4)$ & $5(2)$ & $13(5)$ & $34^{\mathrm{b}}$ \\
$\begin{array}{l}\text { Unknown } \\
\text { Total }\end{array}$ & $102(34)$ & $39(49)$ & $54(25)$ & $37(13)$ & 232 \\
& $298(100)$ & $79(100)$ & $218(100)$ & $282(100)$ & 877 \\
\hline
\end{tabular}



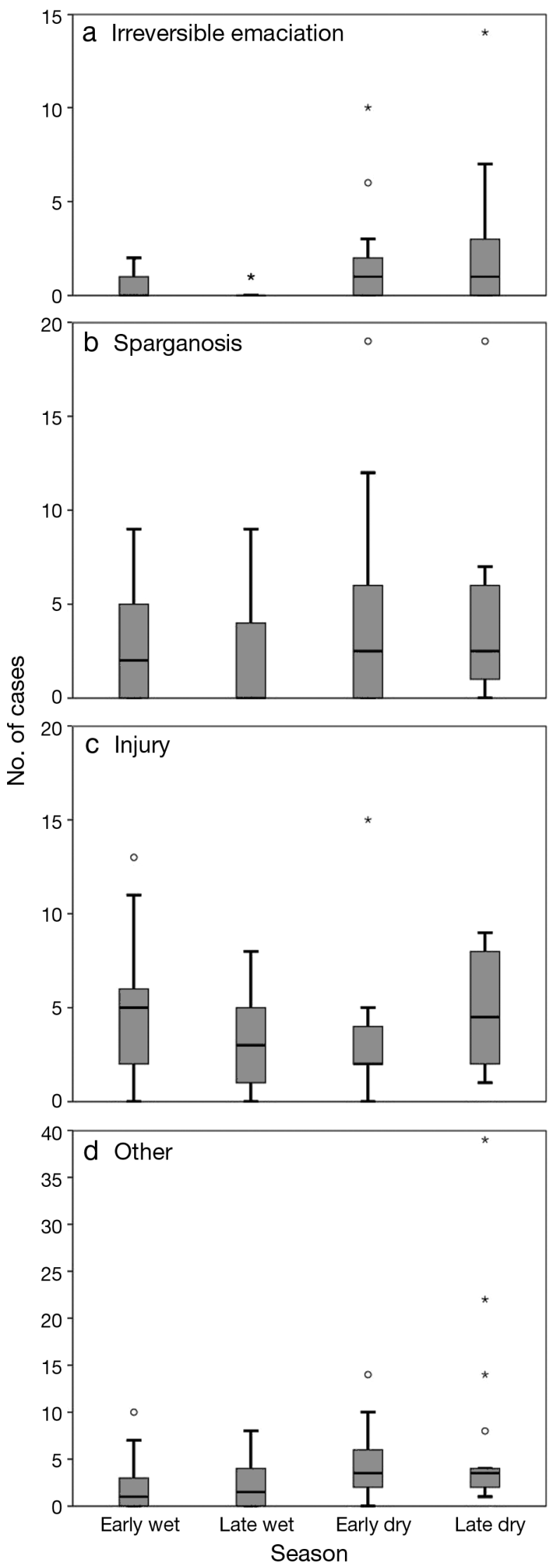

Fig. 3. Litoria infrafrenata. Distribution of white-lipped tree frog cases submitted to the Cairns Frog Hospital each season from January 1999 to December 2004 for each of the 4 presenting categories: (a) irreversible emaciation, (b) sparganosis, (c) injury, (d) 'other'. Each box length represents the inter-quartile range (IQR, 25-75\%) the line inside the box is the median value, and the whiskers go to $1.5 \mathrm{IQR}$. $\circ$ : outliers >1.5 IQR, *: outliers > $3 \mathrm{IQR}$

fairly consistent among origin groups, and no significant differences were found ( $p>0.05$ in all cases; Fig. 4).

The annual proportion of cases submitted over the 6 yr period did not change significantly for total case numbers $(p=0.168)$ or for any of the presenting categories: injury ( $\mathrm{p}=0.669)$, irreversible emaciation $(\mathrm{p}=$ 0.573), sparganosis $(\mathrm{p}=0.293)$, and 'other' ( $\mathrm{p}=$ 0.224 ). Similarly, the annual proportion of cases submitted from each origin category over the same period did not change significantly for total case numbers $(p=0.199)$ or for any of the presenting categories: injury ( $p=0.199)$, irreversible emaciation $(p=$ 0.199), sparganosis $(\mathrm{p}=0.199)$, and 'other' $(\mathrm{p}=$ 0.199).

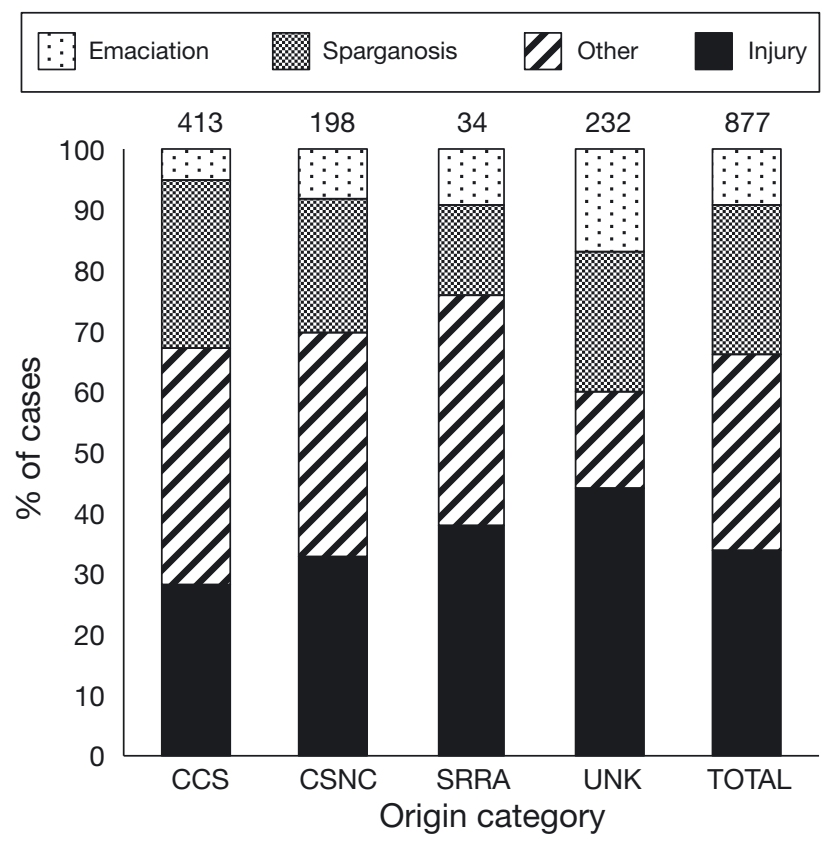

Fig. 4. Litoria infrafrenata. Relative percentage of whitelipped tree frogs submitted to the Cairns Frog Hospital for the 4 presenting categories within each origin over 6 yr from January 1999 to December 2004. Numbers above the stacked bars represent total cases from each origin category. CCS: Cairns city suburbs; CSNC: coastal suburbs north of Cairns; SRRA: surrounding rural and remote areas; UNK: unknown origin 
The clinical syndrome of irreversible emaciation in Litoria infrafrenata was defined as individuals presenting in poor body condition with no obvious clinical cause which failed to respond to basic supportive nutritional care (Fig. 5). Frogs with irreversible emaciation originated predominantly from urban areas, although cases were documented over a wide geographic area of Queensland from the Cairns area, north to Cooktown, south to Townsville and west to the Atherton Tablelands. Cases maintained in captivity post-submission became progressively emaciated, despite occasional force-feeding of invertebrates and repeated shallow immersion in praziquantel (50 $\mathrm{mg} \mathrm{l}^{-1}$ suspension for $30 \mathrm{~min}$ every 14 to $28 \mathrm{~d}_{\text {; }}$ Droncit ${ }^{\circledR} 50 \mathrm{mg}$ tablets, Bayer Australia) for those with visible Spirometra erinacei infection. The majority of affected individuals died over a period of weeks to months post-submission.

Necropsy of 14 specimens presenting with irreversible emaciation showed few gross abnormalities other than generalized emaciation, depletion of fat bodies and heavy burdens of Spirometra erinacei (100\%). Sparganosis was clinically evident prior to necropsy in only $43 \%$ of emaciated frogs. Plerocercoids were found predominantly overlying and within the thigh muscles (86\%; Fig. 6) and also in the celomic cavity (14\%) and dorsal musculature (7\%). In $50 \%$ of cases, there were concurrent infections with other parasites including Rhabdias spp. and intestinal nematodes. Histological examination of tissue sections showed consistent and severe necrosis of muscle tissue around $S$. erinacei plerocercoids (Fig. 7). In some cases (21\%), there was also extensive dystrophic calcification but no inflammatory reaction (Fig. 8). An inflammatory

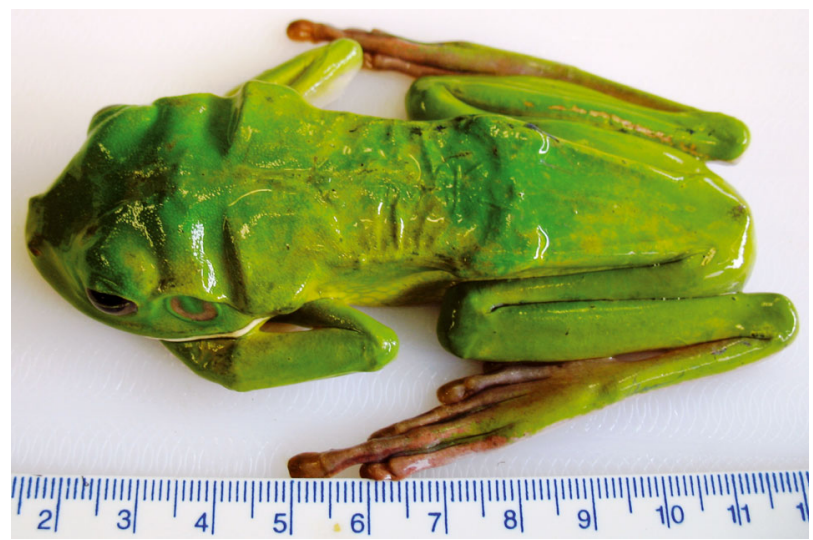

Fig. 5. Litoria infrafrenata. Adult white-lipped tree frog with irreversible emaciation of unknown etiology, in the terminal stages of the disease. Scale $=\mathrm{cm} / \mathrm{mm}$

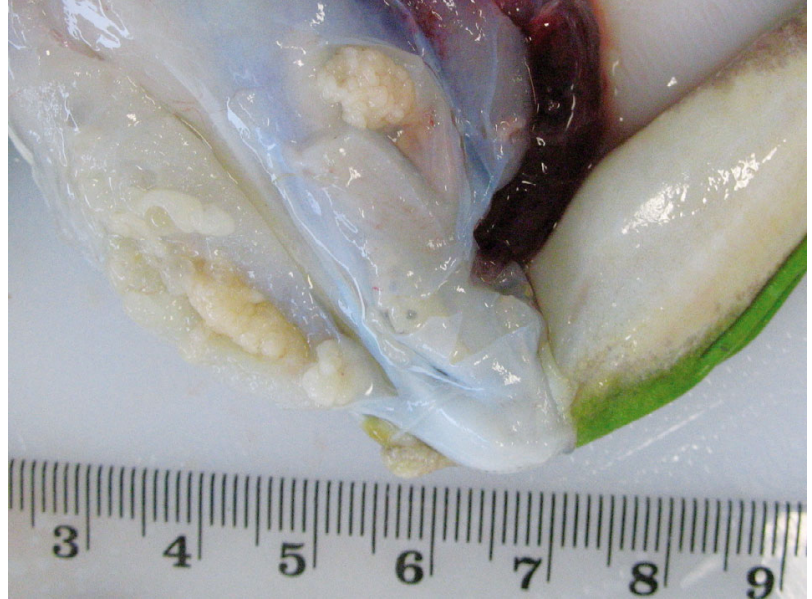

Fig. 6. Litoria infrafrenata infected by Spirometra erinacei. Adult white-lipped tree frog with severe sparganosis. The skin was reflected at necropsy to expose the right medial thigh muscles, and there are multiple $S$. erinacei plerocercoids present subcutaneously and intramuscularly, along with severe swelling and intramuscular hemorrhage. Scale $=\mathrm{cm} / \mathrm{mm}$

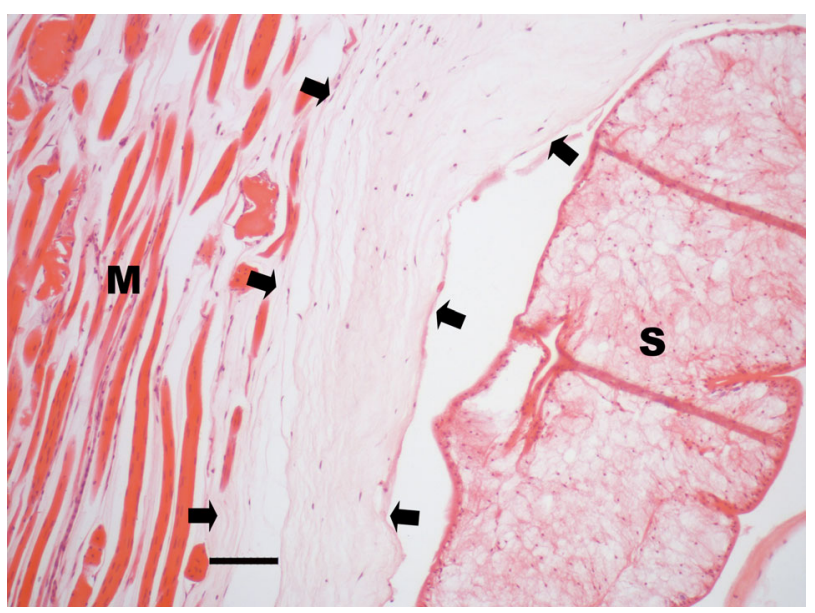

Fig. 7. Litoria infrafrenata infected by Spirometra erinacei. Histological section of thigh muscle from a white-lipped tree frog with irreversible emaciation and concurrent severe sparganosis. Note the severe and widespread necrosis of myocytes and mild fibrosis around the $S$. erinacei plerocercoid (region between the arrows) and the absence of a host inflammatory response. M: muscle; S: sparganum. Stained with hematoxylin and eosin; scale bar $=10 \mu \mathrm{m}$

response was only observed in $21 \%$ of cases, all of which had focal ulcerative dermatitis and bacterial infections secondary to $S$. erinacei infection. These cases had lymphocytic inflammatory infiltrates, with few macrophages and neutrophils. Changes consistent with severe emaciation included abundant hepatic melano-macrophages and concurrent 


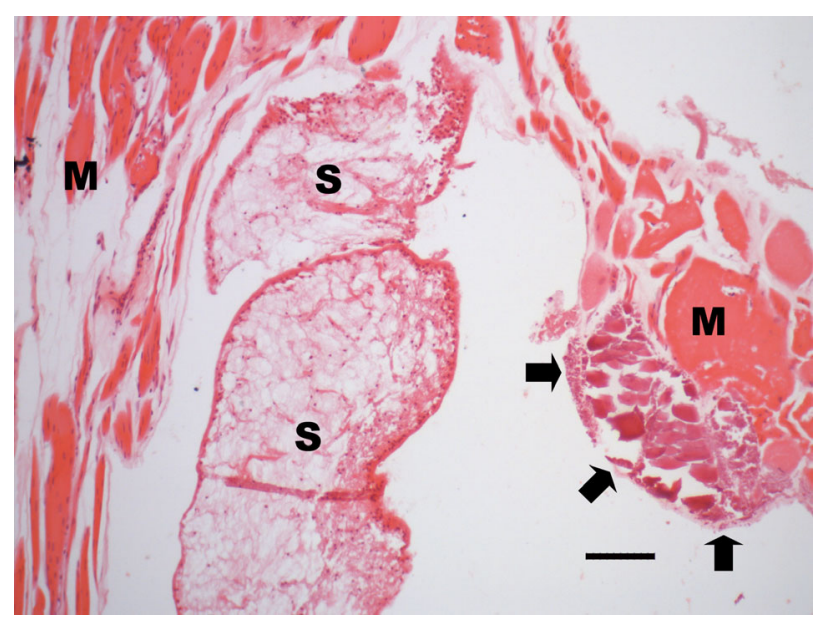

Fig. 8. Litoria infrafrenata infected by Spirometra erinacei. Histological section of thigh muscle from a white-lipped tree frog with irreversible emaciation and concurrent severe sparganosis. Note the severe and widespread necrosis of myocytes around the $S$. erinacei plerocercoid, and the area of associated dystrophic calcification (arrows). M: muscle; S: sparganum. Stained with hematoxylin and eosin; scale bar $=10 \mu \mathrm{m}$

chronic hepatitis in $64 \%$ of cases, and severely depleted atrioventricular groove adipose cells in $70 \%$ of cases. Chronic pneumonitis with focal hypertrophy of pulmonary tissue occurred in $29 \%$ of cases, often $(67 \%)$ associated with the presence of numerous Rhabdias spp. larvae. Other parasites found included myocardial protozoa $(7 \%)$, renal trematodes $(21 \%)$ associated with severe necrotic glomerulonephritis and gastrointestinal mucosal nematodes $(7 \%)$. Lymphocytic and monocytic inflammatory reactions occurred in response to these parasites.

There was an overall prevalence of visible Spirometra erinacei infection in $27 \%$ of frogs. Visible concurrent sparganosis was present in $28 \%$ of cases presenting with irreversible emaciation, but this was not significantly different from the prevalence of visible sparganosis in diseased frogs without emaciation in the 'other' category $(25 \%)$. S. erinacei occurred predominantly in one or both thigh muscles, and occasionally in subcutaneous locations over the body.

A significant association was found between cases with sparganosis and those presenting with irreversible emaciation, compared with the injury group (frogs that appeared clinically healthy apart from the injury; OR 2.489, $\mathrm{p}=0.002$ ). There was no significant association between cases with sparganosis and those presenting in the 'other' category, compared with the injury group (OR $0.823, \mathrm{p}=0.490$ ).

\section{DISCUSSION}

We identified a high overall prevalence of Spirometra erinacei infection $(27 \%)$ in Litoria infrafrenata from northern Queensland submitted to the CFH over a 6 yr period. This is the first report of $L$. infrafrenata as a host of this cestode. We also identified a previously undescribed disease syndrome presenting as irreversible emaciation in $L$. infrafrenata. We found a significant association between this disease syndrome and $S$. erinacei infection and suggest that the parasite is an important primary etiological agent that may cause pathogenic emaciation in L. infrafrenata. Furthermore, we found that while community wildlife care groups can play a valuable role in disease surveillance, there are limitations that make it critical that trained professionals be involved in establishing case definitions and in diagnostic pathology, complementary active disease surveillance, and data analysis and interpretation in all wildlife disease investigations.

Heavy burdens of Spirometra erinacei can cause severe debilitating disease in other free-ranging Litoria spp. (Berger et al. 2009). S. erinacei plerocercoids have a predilection for the muscle and connective tissue of the thighs in frogs, and host response ranges from little or no inflammation (Berger et al. 2009) to severe chronic localized inflammation (Bennett 1978). Bennett (1978) found 3.7\% incidence of $S$. erinacei infection in a group of 1000 Bufo marinus from Queensland, and Berger et al. (2009) found infection in $4.9 \%(12 / 243)$ of sick frogs surveyed in New South Wales and Queensland. In $7 / 12$ of these sick frogs, heavy plerocercoid burdens were associated with debilitating lesions, whereas light burdens in 5/12 frogs were considered incidental to other diseases. A high incidence of $S$. erinacei infection (32\%) was found in Rana limnocharis in Taiwan, but infection was absent in 3 other species surveyed, indicating species-specific differences in susceptibility to infection (Ooi et al. 2000). A survey in Malaysia for Spirometra sp. infection found $21.5 \%$ incidence in $R$. cancrivora and $8.8 \%$ in $R$. limnocharis (Mastura et al. 1996). Of the 112 infected frogs surveyed, $36.6 \%$ had visible swelling and hemorrhage at the sites of infection, but this was not characterized histologically.

Cases of Litoria infrafrenata with irreversible emaciation and Spirometra erinacei infection were documented over a wide geographic area of Queensland. Locations were scattered throughout the entire range of $L$. infrafrenata, indicating that local populations, and potentially the species, could be negatively 
affected. Affected frogs originated predominantly from urban areas due to their proximity to the $\mathrm{CFH}$, but the proportion of frogs submitted with irreversible emaciation did not differ between urban and rural areas.

In $28 \%$ of the 79 emaciated frogs, concurrent Spirometra erinacei infections were found when diagnosis was based on visual inspection of live specimens by CFH staff. However, 14 cases (18\% of emaciated frogs) that were necropsied by a veterinary pathologist all had heavy burdens of spargana. Due to advanced gross pathology, a greater proportion of the necropsied frogs had externally visible spargana, compared with the total number of emaciated frogs, but this was still below $50 \%$. Hence, the proportion of cases with $S$. erinacei infection in the survey was underestimated, as visual examination did not detect sub-clinical or deep tissue infections. Similarly, a survey in Malaysia found no visible external signs of Spirometra sp. infection in $42.9 \%$ of infected frogs (Mastura et al. 1996). This stresses the importance of professionals being involved in disease surveillance for accurate diagnoses, particularly to ensure high diagnostic sensitivity.

Despite the lack of diagnostic sensitivity of the passive surveillance data collected, our findings suggest that Spirometra erinacei is a newly discovered primary pathogen in Litoria infrafrenata that may cause the disease syndrome identified as irreversible emaciation. The lack of host inflammatory reaction to plerocercoids seen histologically in this study and previously by Berger et al. (2009) may be due to the active excretory-secretory molecules of $S$. erinacei plerocercoids evading host immunity (Yang 2003). The relatively high number of diseased individuals presenting with $S$. erinacei infection without emaciation $(25 \%)$ may represent frogs with lighter parasite burdens before loss of body condition occurs. While further controlled experimental and epidemiological studies are needed to confirm this hypothesis, the significant association between sparganosis and irreversible emaciation compared with injured frogs suggests that the parasite may be a primary cause of pathological emaciation. The lack of significant spatial patterns or temporal trends in case presentation indicates that this is probably not an emerging disease, and that the data represent either the baseline prevalence of an endemic disease or a newly established disease that emerged prior to the period of data collection. Identification of spatial and temporal clustering and their specific patterns can assist in etiological disease investigations and identification of areas for further investigation. Disease epidemics represent spatial and temporal clustering of cases, with a 'contagious' spatial pattern, versus the random spatial distribution of sporadic outbreaks and the regular spatial occurrence of endemic disease (Thrusfield 2007).

Alternative primary or secondary causes of the irreversible emaciation syndrome in Litoria infrafrenata include chronic severe malnutrition, environmental pollution, other toxicoses and aging, together with inadequate supportive husbandry. These factors can cause acquired immunodeficiencies and result in increased susceptibility to a range of secondary infections (Roitt 1991). Viruses, such as the Retroviridae, commonly cause immunosuppression in other vertebrates (Herniou et al. 1998, Bielitzki 1999, Kennedy-Stoskopf 1999), but exogenous infectious retroviruses have not been documented as a cause of disease in amphibians to date.

Two formidable infectious emerging diseases are recognized in amphibians worldwide. Chytridiomycosis and ranaviral infections can cause mass mortalities, and the spread of chytridiomycosis has caused widespread amphibian population declines (Berger et al. 1998, Lips et al. 2006, Schloegel et al. 2006, Skerratt et al. 2007). Although these diseases are present in Australia, neither was found to be the cause of disease in the Litoria infrafrenata specimens in this retrospective study. Chytridiomycosis and Bohle iridovirus cause acute, severe clinical signs that did not occur in the cases submitted to the $\mathrm{CFH}_{\text {; }}$ they have not been associated with injury, sparganosis or chronic irreversible emaciation (Cullen et al. 1995, Berger et al. 1998, 1999, Nichols et al. 2001). Furthermore, diagnostic histology and immunostaining of tissues from the 14 irreversibly emaciated specimens did not detect these 2 diseases.

The greater number of Litoria infrafrenata cases presenting with injury during the early wet season, although not statistically significant, may be due to the increased movement of frogs during the breeding season and thus an increased chance of encounter with motor vehicles. Northern Queensland receives $75 \%$ of its annual rainfall between November and April. The increased number of cases submitted during the early and late dry seasons, compared with the late wet season, may be due to the seasonal stress of reduced food and water availability compounded by habitat destruction. Frog population numbers fluctuate seasonally, with maximum numbers likely to occur during the early and late wet seasons when recruitment occurs. This suggests that the increased number of cases submitted during the early and late dry seasons is a real phenomenon and not just a 
reflection of population size. However, frogs also become more visible to the public as they seek permanent water and food sources associated with humans at this time of year, which may result in increased submissions. Although the majority of frogs were received from urban areas, the prevalence of presenting categories was consistent between all of the origin categories, suggesting that there was no significant effect of location on relative disease prevalence. The increased cases presenting with irreversible emaciation during the late dry season compared with the early dry season may be partially due to seasonal variation in host-pathogen interaction and/or pathogen abundance. It may also simply represent the effects of decreased prey abundance leading to chronic malnutrition as the dry season progresses.

The syndrome manifesting as irreversible emaciation in Litoria infrafrenata was discovered through analysis of data collected during passive surveillance by the $\mathrm{CFH}$. While community wildlife groups can play a valuable role in disease surveillance, there are important limitations associated with passive syndromic surveillance alone as a primary tool in the investigation and management of wildlife diseases, including inherent sample bias and data inaccessibility and non-uniformity (Harden et al. 2006, Pacioni et al. 2007). It is clear from our study that the system of community groups carrying out passive syndromic surveillance without adequate diagnostic pathology is fundamentally flawed since accurate definitive diagnoses are not possible. We show that when this system of surveillance is combined with professional diagnostic expertise and active disease surveillance, useful investigations can be initiated to determine whether disease syndromes identified by community groups are novel and whether their incidence is increasing. Indeed, community reporting of amphibian mortality events to professional organizations in England prompted active investigations that diagnosed a novel pathogenic iridovirus (Cunningham et al. 1996).

Data collected through passive syndromic surveillance alone is largely limited to screening purposes, to determine background levels and monitor trends. The quality and usefulness of the data is compromised if it is allowed to accumulate without analysis and real-time reporting. The strong bias towards wildlife in urban areas, with little chance of detecting disease in pristine areas, is another important limitation of passive syndromic surveillance identified previously (Harden et al. 2006), and this can be compounded by media interests. Amphibian population declines and extinctions due to chytridiomycosis were only detected in many remote areas through active surveillance techniques (McDonald 1994, Berger et al. 1998, Lips et al. 2006, Schloegel et al. 2006). Finally, there is a reduced chance of detecting acute mortalities with passive surveillance, and epidemiological data, including prevalence data, for affected populations is lacking. Emerging diseases with high rates of rapid mortalities in affected animals may be missed using this method of surveillance. These factors highlight the need for concurrent active surveillance and the involvement of pathologists, epidemiologists and other experts during disease investigations. In addition to professionals providing accurate clinical and pathological diagnoses, the quality of disease surveillance data collected by community wildlife groups could be greatly improved by the use of real-time computerized reporting systems, with standardized terminology and established syndromic case definitions, integrated with a national database such as that maintained by the AWHN.

Future research should investigate the etiology and epidemiology of the irreversible emaciation syndrome in Litoria infrafrenata, especially the role of Spirometra erinacei infection, along with the broader impact of $S$. erinacei as a primary pathogen on frog populations. An active surveillance system is needed to determine distribution and prevalence of the disease and to identify risk factors, e.g. age, host population density, and domestic animal population density. The results should be compared with passive surveillance data to further assess the benefits and limitations of both methods of surveillance and the significance of the disease to amphibian populations in northern Australia. The emaciation syndrome could affect the abundance of $L$. infrafrenata, and further investigations will contribute to the broader understanding of the role of emerging and endemic diseases in the decline of amphibians.

Acknowledgements. We thank the Australian Government Department of the Environment and Heritage and the Australian Wildlife Health Network for provision of funding for this project, and the Cairns Frog Hospital for provision of submission records for analysis.

\section{LITERATURE CITED}

Bennett LJ (1978) The immunological responses of amphibians to Australian spargana. J Parasitol 64:756-759

Berger L, Speare R, Daszak P, Green DE and others (1998) Chytridiomycosis causes amphibian mortality associated with population declines in the rainforests of Australia and Central America. Proc Natl Acad Sci USA 95: 9031-9036 
Berger L, Speare R, Hyatt A (1999) Chytrid fungi and amphibian declines: overview, implications and future directions. In: Campbell A (ed) Declines and disappearances of Australian frogs. Environment Australia, Canberra, p 23-33

Berger L, Skerratt L, Zhu XQ, Young S, Speare R (2009) Severe sparganosis in Australian tree frogs. J Wildl Dis 45:921-929

Bielitzki JT (1999) Emerging viral diseases of nonhuman primates. In: Fowler ME, Miller RE (eds) Zoo and wild animal medicine current therapy IV. WB Saunders Company, Philadelphia, PA, p 377-382

Cogger HG (2000) Reptiles and amphibians of Australia. New Holland Publishers (Australia), Sydney

$>$ Cullen BR, Owens L, Whittington RJ (1995) Experimental infection of Australian anurans (Limnodynastes terraereginae and Litoria latopalmata) with Bohle iridovirus. Dis Aquat Org 23:83-92

Cunningham AA, Langton TES, Bennett PM, Lewin JF, Drury SE, Gough RE, Macgregor SK (1996) Pathological and microbiological findings from incidents of unusual mortality of the common frog (Rana temporaria). Philos Trans R Soc Lond B Biol Sci 351:1539-1557

Daly JJ (1982) Sparganosis. In: Steele JJ (ed) Parasitic zonoses, Vol I. CRC handbook series in zoonoses, Section C. CRC Press, Boca Raton, FL, p 293-312

$>$ Daszak P, Cunningham AA, Hyatt AD (2000) Emerging infectious diseases of wildlife - threats to biodiversity and human health. Science 287:443-449

Daszak P, Cunningham AA, Hyatt AD (2003) Infectious disease and amphibian population declines. Divers Distrib 9:141-150

Harden J, Dickerman R, Penn Elliston E (2006) Collection, value, and use of wildlife rehabilitation data. J Wildl Rehab 28:10-28

Herniou E, Martin J, Miller K, Cook J, Wilkinson M, Tristem M (1998) Retroviral diversity and distribution in vertebrates. J Virol 72:5955-5966

IUCN (2010) IUCN Red List of Threatened Species, Version 2010.2. Available at www.iucnredlist.org (accessed 9 July 2010)

Kennedy-Stoskopf S (1999) Emerging viral infections in large cats. In: Fowler ME, Miller RE (eds) Zoo and wild animal medicine current therapy IV. WB Saunders Company, Philadelphia, PA, p 401-410

Lips KR, Brem F, Brenes R, Reeve JD and others (2006) Emerging infectious disease and the loss of biodiversity in a Neotropical amphibian community. Proc Natl Acad Sci USA 103:3165-3170

Little S, Ambrose D (2000) Spirometra infection in cats and dogs. Compend Contin Educ Pract Vet 22:299-303

Editorial responsibility: Alex Hyatt, Geelong, Victoria, Australia
Mastura AB, Ambu S, Hasnah O, Rosli R (1996) Spargana infection of frogs in Malaysia. Southeast Asian J Trop Med Public Health 27:51-52

McDonald KR (1994) Declining frog populations in the wet tropics. Internal Report, Conservation Strategy Branch. Government Department of the Environment and Heritage, Atherton

Nichols DK, Lamirande EW, Pessier AP, Longcore JE (2001) Experimental transmission of cutaneous chytridiomycosis in dendrobatid frogs. J Wildl Dis 37:1-11

Ooi HK, Chang SL, Huang CC, Kawakami Y, Uchida A (2000) Survey of Spirometra erinaceieuropaei in frogs in Taiwan and its experimental infection in cats. $\mathrm{J}$ Helminthol 74:173-176

Pacioni C, Trocini S, Warren K, Butcher J, Robertson I (2007) Wildlife disease passive surveillance: Are wildlife rehabilitation centres a tool? A case study. [Abstract] In: Health monitoring and disease investigation in population management and species recovery programs. Proceedings of the Wildlife Disease Association (Australasian section) conference. WDA, Perth, p 63

Rice WR (1989) Analyzing tables of statistical tests. Evolution 43:223-225

Roitt I (1991) Essential immunology. Blackwell Scientific Publications, Oxford

Schloegel LM, Hero JM, Berger L, Speare R, McDonald K, Daszak P (2006) The decline of the sharp-snouted day frog: the first documented case of extinction by infection in a free-ranging wildlife species? EcoHealth 3:35-40

Skerratt LF, Berger L, Speare R, Cashins S and others (2007) Spread of chytridiomycosis has caused the rapid global decline and extinction of frogs. EcoHealth 4:125-134

Stuart SN, Chanson JS, Cox NA, Young BE, Rodrigues AS, Fischman DL, Waller RW (2004) Status and trends of amphibian declines and extinctions worldwide. Science 306:1783-1786

Thrusfield M (2007) Veterinary epidemiology. Blackwell Science, Oxford

Vié JC, Hilton-Taylor C, Stuart SN (2009) Wildlife in a changing world - an analysis of the 2008 IUCN Red List of Threatened Species. International Union for Conservation of Nature, Gland

Yang HJ (2003) Comparison of carbohydrate moieties of sparganum proteins of the snake, mouse and those of adult worm. Korean J Parasitol 41:135-137

Zhu XQ, Beveridge I, Berger L, Barton D, Gasser RB (2002) Single-strand conformation polymorphism-based analysis reveals genetic variation within Spirometra erinacei (Cestoda: Pseudophyllidea) from Australia. Mol Cell Probes 16:159-165

Submitted: July 19, 2010; Accepted: October 4, 2011 Proofs received from author(s): January 21, 2012 